\title{
Simultaneous Determination of Six Major Constituents of the Herbal Formula Insampaedok-san Using HPLC-PDA
}

\author{
Chang-Seob Seo, Jung Hoon Kim, and Hyeun-Kyoo Shin \\ Basic Herbal Medicine Research Group, Herbal Medicine Research Division, Korea Institute of Oriental Medicine, \\ 1672 Yuseongdae-ro, Yuseong-gu, Daejeon 305-811, Republic of Korea
}

Correspondence should be addressed to Hyeun-Kyoo Shin, hkshin@kiom.re.kr

Received 24 May 2012; Accepted 18 June 2012

Academic Editors: P. Campíns-Falcó and C. Desiderio

Copyright () 2012 Chang-Seob Seo et al. This is an open access article distributed under the Creative Commons Attribution License, which permits unrestricted use, distribution, and reproduction in any medium, provided the original work is properly cited.

\begin{abstract}
A simple, rapid, and accurate high-performance liquid chromatographic method was applied to the quantitative analysis of six components of a traditional herbal formulation, Insampaedok-san (ISPDS): liquiritin (1), ferulic acid (2), naringin (3), hesperidin (4), neohesperidin (5), and glycyrrhizin (6). The six components were separated within 35 min using a Gemini $\mathrm{C}_{18}$ column maintained at $40^{\circ} \mathrm{C}$. The mobile phase was composed of $1.0 \%(\mathrm{v} / \mathrm{v})$ aqueous acetic acid (A) and $1.0 \%(\mathrm{v} / \mathrm{v})$ acetic acid in acetonitrile (B) by gradient elution. The flow rate was $1.0 \mathrm{~mL} / \mathrm{min}$ and the detector was a photodiode array (PDA) set at 254, 280 , and $320 \mathrm{~nm}$. The calibration curves showed good linearity $\left(R^{2}=1.0000\right)$ for different concentration ranges. The recovery of each component was in the range of $92.62 \%-105.96 \%$, with a relative standard deviation (RSD) of less than $4.0 \%$. The RSDs for intra- and interday precision were $0.04 \%-1.70 \%$ and $0.06 \%-2.56 \%$, respectively. The concentration of each of the six components of ISPDS was in the range $0.72-9.88 \mathrm{mg} \mathrm{g}^{-1}$.
\end{abstract}

\section{Introduction}

Herbal Medicines, including herbal formulas and prescriptions, have long been used in Korea, China, Japan, and other Asian countries to prevent and treat various diseases. These herbal medicines have few side effects and exhibit multiple activities [1-3]. Insampaedok-san (ISPDS), a traditional Korean herbal prescription, is a renowned remedy used for the treatment of the common cold and influenza presenting with fever, chills, headache, muscular pain, and cough [4]. ISPDS contains 12 species of medicinal herb (Table 1) and exhibits biological activity, such as anti-inflammatory [5], analgesia [6], antipyresis [6], and neuroprotective [7] effects. Recently, reports on its safety have included consideration of acute toxicity [8,9]. In addition, the simultaneous analysis of four constituents of fermented ISPDS using high-performance liquid chromatography (HPLC) has been reported [7]. However, this method conducted simultaneous analysis of fermented ISPDS using Lactobacillus casei KFRI 129 , and required a long separation time for the constituents of about $65 \mathrm{~min}$. There have been few reports on the quality control of the components of ISPDS, excluding research by Weon et al. [7]. Therefore, we conducted simultaneous determination of the major components for the quality control of ISPDS using a simple, rapid, and accurate HPLCPDA method. Currently, HPLC is frequently coupled with a photodiode array (PDA) detector, because it is a convenient and widely applicable method for the rapid separation and identification of multiple components of herbal extracts and medicines $[1,10,11]$.

In this study, we performed a quantitative determination and method validation using the HPLC-PDA method for six components of ISPDS: four flavonoids (liquiritin (1), naringin (3), hesperidin (4), and neohesperidin (5)), one phenolic acid (ferulic acid (2)), and one triterpenoid saponin (glycyrrhizin (6)) (Figure 1).

\section{Experimental}

2.1. Reagents and Materials. The reference compounds $\mathbf{1}$, 4, and $\mathbf{5}$ were purchased from NPC BioTechnology Inc. 
<smiles></smiles>

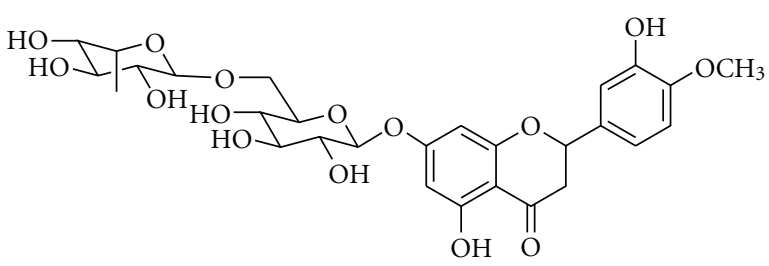

3

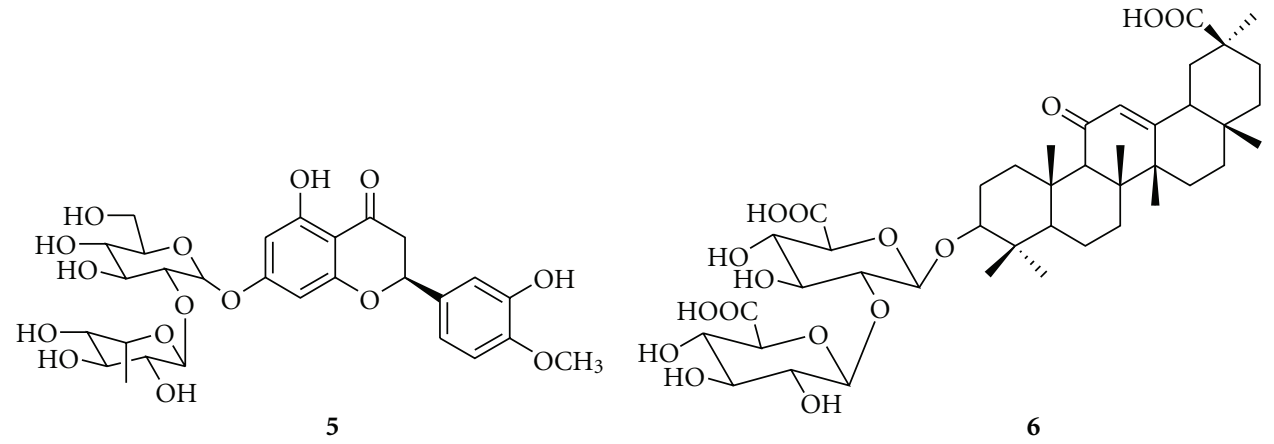

Figure 1: Chemical structure of the six marker compounds 1-6 in Insampaedok-san.

TABLE 1: Crude components of Insampaedok-san.

\begin{tabular}{lcccc}
\hline Scientific name & Latin name & Amount $(\mathrm{g})$ & Company of purchase & Source \\
\hline Panax ginseng & Ginseng radix alba & 3.75 & Omniherb & Geumsan, Korea \\
Bupleurum falcatum & Bupleuri radix & 3.75 & HMAX & China \\
Angelica decursiva & Angelicae decursivae radix & 3.75 & HMAX & China \\
Ostericum koreanum & Osterici radix & 3.75 & HMAX & Ymniherb \\
Aralia continentalis & Araliae continentalis radix & 3.75 & HMAX & China \\
Citrus aurantium & Aurantii fructus immaturus & 3.75 & Omniherb & Yeongcheon, Korea \\
Platycodon grandiflorum & Platycodi radix & 3.75 & Omniherb & Yeongcheon, Korea \\
Cnidium officinale & Cnidii rhizoma & 3.75 & HMAX & China \\
Poria cocos & Hoelen & 3.75 & HMAX & China \\
Glycyrrhiza uralensis & Glycyrrhizae radix & 3.75 & Omniherb & Yeongcheon, Korea \\
Mentha arvensis & Menthae herba & 3.75 & Omniherb & Yeongcheon, Korea \\
Zingiber officinale & Zingiberis rhizoma crudus & 3.75 & & \\
\hline Total amount & & 45.00 & &
\end{tabular}

(Daejeon, Republic of Korea), Biopurify Phytochemicals Ltd (Chengdu, China), and ChromaDex (Irvine, CA, USA), respectively. Compounds 2, 3, and 6 were obtained from Wako Chemicals (Osaka, Japan). The purity of the six reference standards was at least $98.0 \%$, according to the HPLC data. The HPLC-grade solvents used-methanol, acetonitrile, and water-were obtained from J.T. Baker (Phillipsburg, NJ, USA). The glacial acetic acid used was<smiles>COc1cc(/C=C/C(=O)O)ccc1O</smiles>

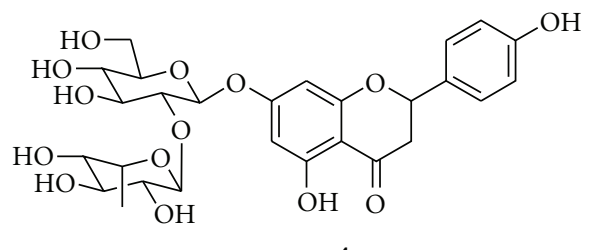

4<smiles>C1CC1</smiles> 

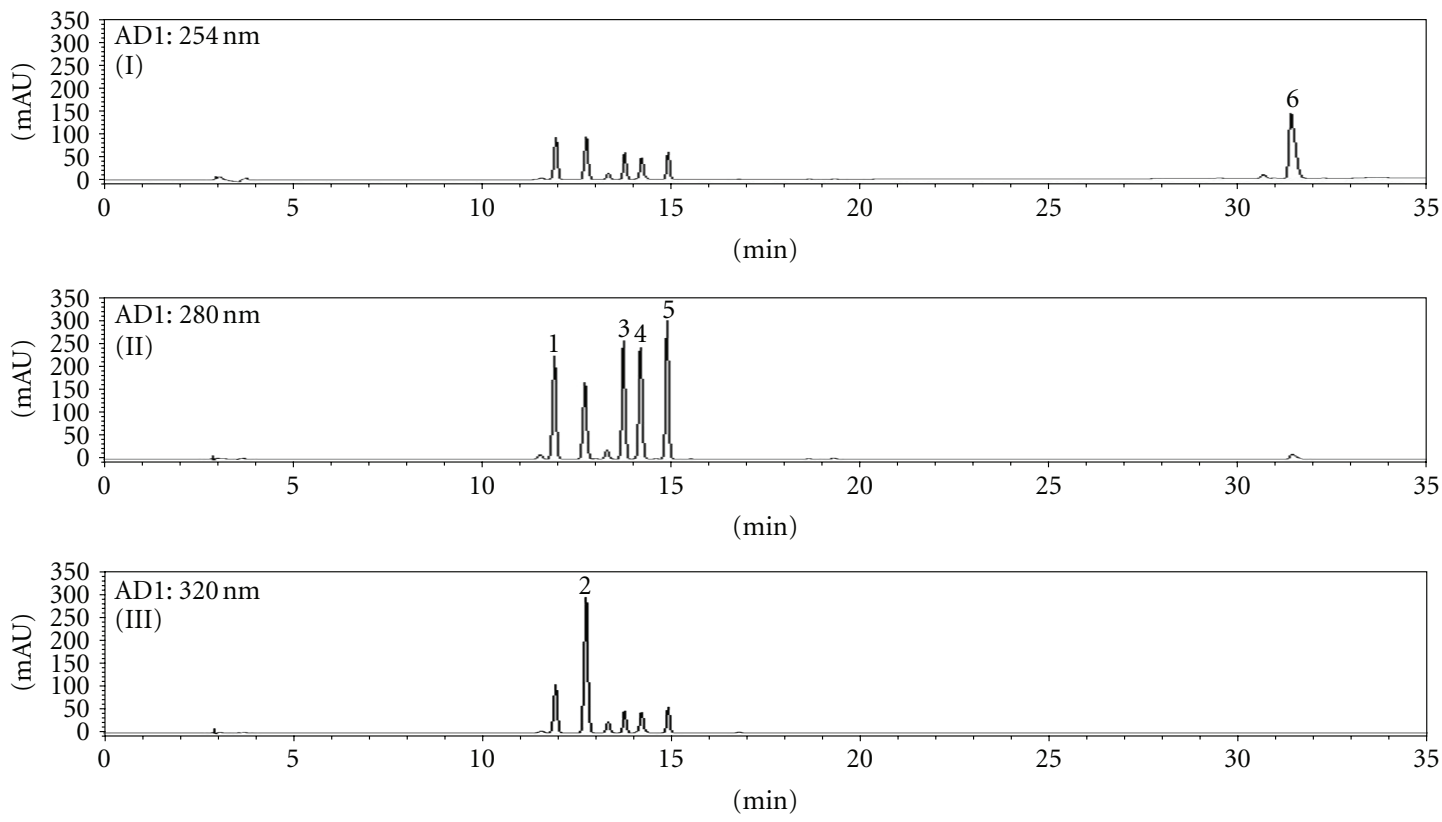

(a)
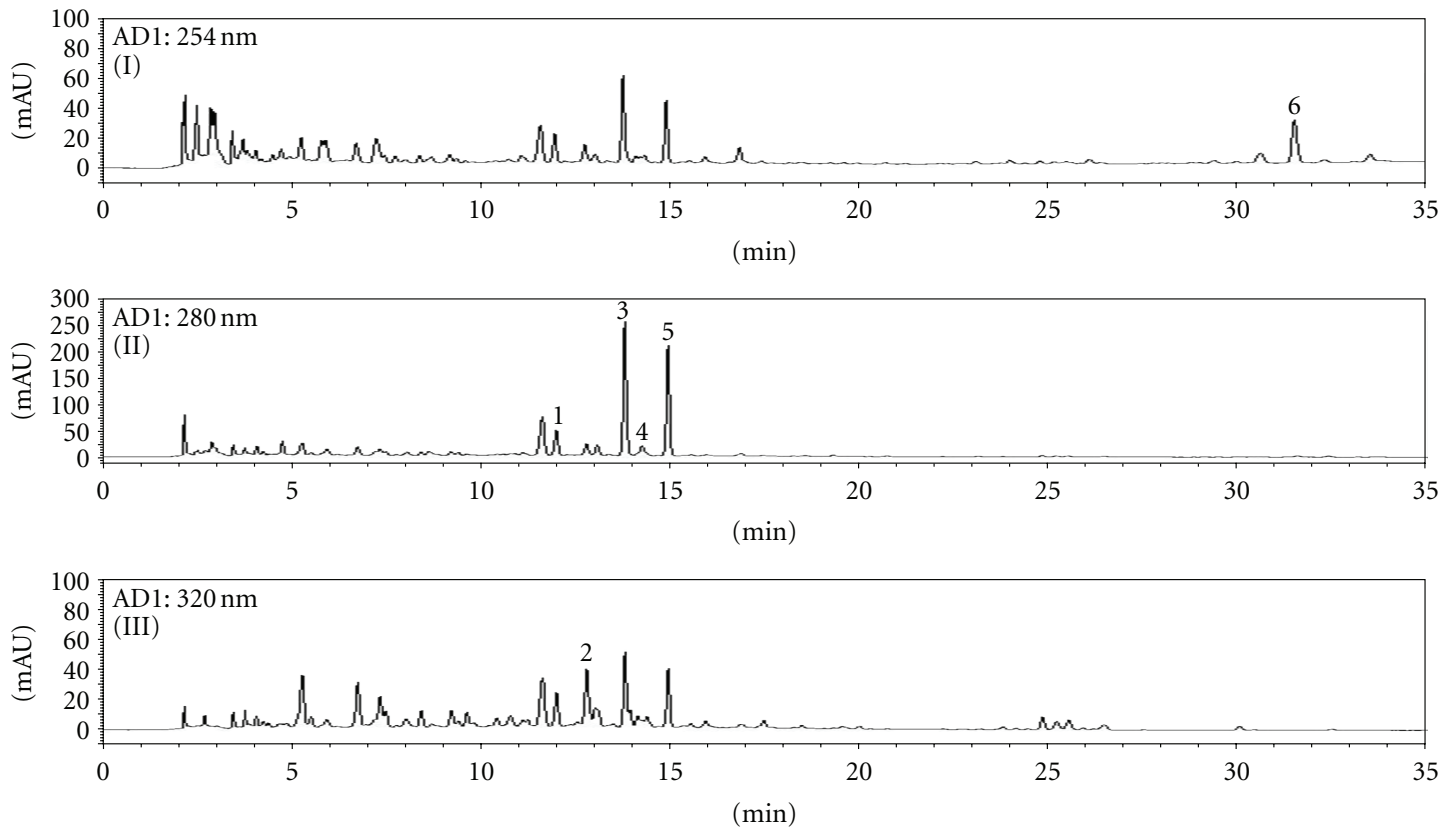

(b)

FIGURE 2: HPLC chromatograms of a standard mixture (a) of six components and Insampaedok-san sample (b), with detection at (I) 254 $\mathrm{nm}$, (II) $280 \mathrm{~nm}$, and (III) $320 \mathrm{~nm}$. The peaks are ascribed to liquiritin (1), ferulic acid (2), naringin (3), hesperidin (4), neohesperidin (5), and glycyrrhizin (6).

Daejeon University, Daejeon, Republic of Korea, respectively. The composition of the ISPDS samples is shown in Table 1. A voucher specimen (2008-KE14-1 through KE14-12) has been deposited at the Basic Herbal Medicine Research Group, Korea Institute of Oriental Medicine.

2.2. Preparation of Standard and Sample Solutions. Standard stock solutions of compounds $\mathbf{1 - 6}$ (all at $1000 \mu \mathrm{g} / \mathrm{mL}$ ) were prepared in methanol and stored below $4^{\circ} \mathrm{C}$. Working standard solutions were prepared by serial dilution of the stock solutions with methanol.

A decoction of ISPDS was prepared in our laboratory from a mixture of chopped crude herbs (Table 1, total weight $=3.51 \mathrm{~kg}$ ), extracted in $35 \mathrm{~L}$ of distilled water at $100^{\circ} \mathrm{C}$ for $2 \mathrm{~h}$ in a herb extractor (COSMOS-660, Kyungseo Machine Co., Inchon, Korea). After filtration using a standard sieve 
TABLE 2: Linearity, correlation coefficient, LOD, and LOQ of the marker compounds $(n=3)$.

\begin{tabular}{|c|c|c|c|c|c|}
\hline Compound & Linear range $\left(\mu \mathrm{g} \mathrm{mL}^{-1}\right)$ & Regression equation $^{\mathrm{a}}$ & Correlation coefficient $\left(R^{2}\right)$ & $\mathrm{LOD}^{\mathrm{b}}\left(\mu \mathrm{g} \mathrm{mL}^{-1}\right)$ & $\mathrm{LOQ}^{\mathrm{c}}\left(\mu \mathrm{g} \mathrm{mL}^{-1}\right)$ \\
\hline 1 & $0.78-100.00$ & $Y=16,546.59 x+327.71$ & 1.0000 & 0.09 & 0.29 \\
\hline 2 & $0.39-50.00$ & $Y=46,824.31 x-4,190.75$ & 1.0000 & 0.03 & 0.09 \\
\hline 3 & $3.13-400.00$ & $Y=15,866.42 x+3,406.43$ & 1.0000 & 0.08 & 0.27 \\
\hline 4 & $0.39-50.00$ & $Y=18,561.95 x-244.18$ & 1.0000 & 0.08 & 0.26 \\
\hline 5 & $1.56-200.00$ & $Y=19,357.24 x+1,447.17$ & 1.0000 & 0.07 & 0.22 \\
\hline 6 & $0.78-100.00$ & $Y=8,513.98 x+1,124.60$ & 1.0000 & 0.09 & 0.31 \\
\hline
\end{tabular}

${ }^{\mathrm{a}} Y=$ peak area $(\mathrm{mAU})$ of the components. $x=$ concentration $\left(\mu \mathrm{g} \mathrm{mL}^{-1}\right)$ of the components.

${ }^{\mathrm{b}} \mathrm{LOD}=3 \times$ signal-to-noise $(\mathrm{S} / \mathrm{N})$ ratio.

${ }^{\mathrm{c}} \mathrm{LOQ}=10 \times$ signal-to-noise $(\mathrm{S} / \mathrm{N})$ ratio.

TABle 3: Precision and accuracy of the analytical results $(n=5)$.

\begin{tabular}{|c|c|c|c|c|c|c|c|}
\hline \multirow{2}{*}{ Compound } & \multirow{2}{*}{$\begin{array}{l}\text { Fortified conc. } \\
\qquad\left(\mu \mathrm{g} \mathrm{mL} \mathrm{m}^{-1}\right)\end{array}$} & \multicolumn{3}{|c|}{ Intraday } & \multicolumn{3}{|c|}{ Interday } \\
\hline & & $\begin{array}{c}\text { Observed conc. } \\
\left(\mu \mathrm{g} \mathrm{mL}^{-1}\right)\end{array}$ & $\begin{array}{c}\text { Precision } \\
(\%)\end{array}$ & $\begin{array}{c}\text { Accuracy } \\
(\%)\end{array}$ & $\begin{array}{c}\text { Observed conc. } \\
\quad\left(\mu \mathrm{g} \mathrm{mL}^{-1}\right)\end{array}$ & $\begin{array}{c}\text { Precision } \\
(\%)\end{array}$ & $\begin{array}{c}\text { Accuracy } \\
(\%)\end{array}$ \\
\hline \multirow{3}{*}{1} & 4.00 & 4.07 & 1.63 & 101.70 & 4.07 & 0.85 & 101.73 \\
\hline & 10.00 & 10.05 & 1.69 & 100.46 & 9.82 & 0.22 & 98.16 \\
\hline & 20.00 & 19.96 & 0.36 & 99.82 & 20.08 & 0.06 & 100.39 \\
\hline \multirow{3}{*}{2} & 2.00 & 1.98 & 0.44 & 99.10 & 2.03 & 1.13 & 101.66 \\
\hline & 4.00 & 3.96 & 1.14 & 99.02 & 4.10 & 2.56 & 102.39 \\
\hline & 8.00 & 8.02 & 0.28 & 100.30 & 7.94 & 0.70 & 99.30 \\
\hline \multirow{3}{*}{3} & 20.00 & 19.70 & 1.22 & 98.50 & 19.21 & 0.80 & 96.04 \\
\hline & 50.00 & 50.21 & 0.60 & 100.42 & 50.11 & 0.23 & 100.21 \\
\hline & 100.00 & 99.96 & 0.12 & 99.96 & 100.11 & 0.08 & 100.11 \\
\hline \multirow{3}{*}{4} & 3.00 & 2.94 & 1.37 & 98.12 & 2.96 & 0.55 & 98.82 \\
\hline & 8.00 & 8.52 & 0.28 & 106.51 & 8.42 & 0.83 & 105.27 \\
\hline & 15.00 & 14.73 & 0.13 & 98.22 & 14.78 & 0.25 & 98.55 \\
\hline \multirow{3}{*}{5} & 10.00 & 10.05 & 1.70 & 100.47 & 9.76 & 0.60 & 97.63 \\
\hline & 35.00 & 34.64 & 1.19 & 98.97 & 34.58 & 0.52 & 98.81 \\
\hline & 70.00 & 70.11 & 0.21 & 100.16 & 70.28 & 0.12 & 100.40 \\
\hline \multirow{3}{*}{6} & 6.00 & 6.34 & 0.82 & 105.67 & 6.34 & 0.84 & 105.62 \\
\hline & 15.00 & 14.50 & 0.20 & 96.64 & 14.44 & 0.65 & 96.29 \\
\hline & 30.00 & 30.18 & 0.04 & 100.61 & 30.21 & 0.13 & 100.70 \\
\hline
\end{tabular}

(no. 270, $53 \mu \mathrm{m}$ ), the solution was evaporated to dryness and freeze-dried $(852.3 \mathrm{~g})$. The yield of the ISPDS extract was $24.28 \%$. For HPLC analysis, lyophilized ISPDS powder (200 mg) was accurately weighed and dissolved in distilled water $(20 \mathrm{~mL})$. All the solutions were filtered through a SmartPor GHP syringe filter (pore size $=0.2 \mu \mathrm{m}$, Woongki Science, Seoul, Korea) before HPLC analysis.

2.3. HPLC Analysis. HPLC analysis was performed using a Shimadzu HPLC system (Shimadzu Co., Kyoto, Japan) equipped with a solvent delivery unit (LC-20AD), online degasser (DGU-20A3), column oven (CTO-20A), autosample injector with cooler (SIL-20AC), and PDA detector (SPDM20A). The data processor used the LC solution software package v.1.24 (Shimadzu Co., Kyoto, Japan). Column separation was carried out using a Gemini $\mathrm{C}_{18}$ analytical column $(250 \times 4.6 \mathrm{~mm}$, particle size $=5 \mu \mathrm{m}$, Phenomenex, Torrance,
CA, USA) and the column temperature was maintained at $40^{\circ} \mathrm{C}$. The mobile phases were $1.0 \%(\mathrm{v} / \mathrm{v})$ aqueous acetic acid (A) and 1.0\% (v/v) acetic acid in acetonitrile (B). The gradient flow was as follows: $(\mathrm{A}) /(\mathrm{B})=85 / 15(0 \mathrm{~min}) \rightarrow$ $(\mathrm{A}) /(\mathrm{B})=35 / 65(40 \mathrm{~min}) \rightarrow(\mathrm{A}) /(\mathrm{B})=0 / 100(45 \mathrm{~min}$, hold for $5 \mathrm{~min}) \rightarrow(\mathrm{A}) /(\mathrm{B})=85 / 15(55 \mathrm{~min}$, hold for $15 \mathrm{~min})$. Analysis was performed using a flow rate of $1.0 \mathrm{~mL} / \mathrm{min}$ and monitored at $254 \mathrm{~nm}$ for compound 6, $280 \mathrm{~nm}$ for compounds $\mathbf{1}$ and 3-5, and $320 \mathrm{~nm}$ for compound 2 . The injection volume used was $10 \mu \mathrm{L}$.

2.4. Linearity, Limits of Detection, and Quantification. Calibration curves of components 1-6 were calculated from the peak areas of standard solutions in the following concentration range: compounds 1 and 6, 0.78-100.00 $\mu \mathrm{g} \mathrm{mL}^{-1}$; compounds 2 and 4, 0.39-50.00 $\mu \mathrm{g} \mathrm{mL}^{-1}$; compound 3, 3.13$400.00 \mu \mathrm{g} \mathrm{mL}^{-1}$; and compound 5, $1.56-200.00 \mu \mathrm{g} \mathrm{mL}^{-1}$. 
TABLE 4: Recovery levels for the six marker compounds $(n=5)$.

\begin{tabular}{|c|c|c|c|c|c|}
\hline Compound & $\begin{array}{l}\text { Original mean level } \\
\left(\mu \mathrm{g} \mathrm{mL}^{-1}\right)\end{array}$ & $\begin{array}{l}\text { Spiked level } \\
\left(\mu \mathrm{g} \mathrm{mL}^{-1}\right)\end{array}$ & $\begin{array}{l}\text { Detected mean level } \\
\qquad\left(\mu \mathrm{g} \mathrm{mL}^{-1}\right)\end{array}$ & $\begin{array}{c}\text { Recovery mean } \\
(\%)\end{array}$ & $\begin{array}{l}\text { RSD } \\
(\%)\end{array}$ \\
\hline \multirow{3}{*}{1} & \multirow{3}{*}{24.91} & 4.00 & 29.03 & 103.19 & 1.62 \\
\hline & & 10.00 & 34.92 & 101.33 & 1.42 \\
\hline & & 20.00 & 45.42 & 102.57 & 0.73 \\
\hline \multirow{3}{*}{2} & \multirow{3}{*}{7.44} & 2.00 & 9.53 & 104.43 & 0.99 \\
\hline & & 4.00 & 11.58 & 103.34 & 0.82 \\
\hline & & 8.00 & 15.40 & 99.50 & 3.89 \\
\hline \multirow{3}{*}{3} & \multirow{3}{*}{104.43} & 20.00 & 124.26 & 99.16 & 1.81 \\
\hline & & 50.00 & 157.15 & 105.46 & 0.63 \\
\hline & & 100.00 & 210.39 & 105.96 & 0.31 \\
\hline \multirow{3}{*}{4} & \multirow{3}{*}{14.55} & 3.00 & 17.56 & 100.46 & 1.04 \\
\hline & & 8.00 & 22.81 & 103.28 & 0.47 \\
\hline & & 15.00 & 28.93 & 95.88 & 1.34 \\
\hline \multirow{3}{*}{5} & \multirow{3}{*}{71.86} & 10.00 & 81.39 & 95.32 & 1.79 \\
\hline & & 35.00 & 106.78 & 99.78 & 0.92 \\
\hline & & 70.00 & 143.45 & 102.27 & 0.33 \\
\hline \multirow{3}{*}{6} & \multirow{3}{*}{33.02} & 6.00 & 39.11 & 101.53 & 1.09 \\
\hline & & 15.00 & 46.91 & 92.62 & 0.73 \\
\hline & & 30.00 & 62.09 & 96.90 & 0.21 \\
\hline
\end{tabular}

Limit of detection (LOD) and limit of quantification (LOQ) were determined based on signal-to-noise $(\mathrm{S} / \mathrm{N})$ ratios of 3 and 10 , respectively.

2.5. Precision and Accuracy. Reproducibility was assessed by analyzing six independently prepared standard solutions. The relative standard deviation (RSD) of the analyte peak areas and peak retention times for each standard were calculated. Intra- and interday precision values were determined using a standard addition method to prepare spiked samples, employing both standards and controls. The accuracy of the HPLC method was estimated from the recovery tests. The recovery tests were performed adding known concentrations (low, medium, and high) of the reference standards to the ISPDS samples. The average recovery value was calculated using the following formula:

Recovery $(\%)=\frac{\left(\text { Amount }_{\text {determined }}-\text { Amount }_{\text {original }}\right)}{\text { Amount }_{\text {spiked }}} \times 100$.

\section{Results and Discussion}

3.1. Optimization of HPLC Separation. We obtained good separation chromatograms using mobile phases consisting of (A) $1.0 \%(\mathrm{v} / \mathrm{v})$ aqueous acetic acid and (B) $1.0 \%$ $(\mathrm{v} / \mathrm{v})$ acetic acid in acetonitrile. Quantitation was achieved using PDA detection in the region $190-400 \mathrm{~nm}$, based on retention times and UV spectra compared with those of the standards. The UV wavelength was recorded at $254 \mathrm{~nm}$ for compound 6, $280 \mathrm{~nm}$ for compounds $\mathbf{1}$ and $\mathbf{3}-\mathbf{5}$, and $320 \mathrm{~nm}$ for compound 2. Using these optimized chromatography conditions, the six components were eluted within a period of $35 \mathrm{~min}$. The retention times of compounds 1-6 were $11.92,14.80,15.55,14.20,14.90$, and $31.35 \mathrm{~min}$, respectively. Representative HPLC chromatograms of standards and the extract are shown in Figure 2.

3.2. Linearity, Range, $L O D$, and $L O Q$. Calibration curves of compounds $\mathbf{1}-\mathbf{6}$ were obtained using standard solutions. The linearity of the peak area $(y)$ versus the concentration $(x$, $\mu \mathrm{g} \mathrm{mL}^{-1}$ ) curve for each component was used to calculate the amount of each main component of ISPDS. All the coefficients $\left(R^{2}\right)$ of determination of the calibration curves for the six constituents were 1.0000 . The linear equations and coefficients $\left(R^{2}\right)$ of determination of the calibration curves are summarized in Table 2. In addition, the LOD and LOQ values were in the range $0.03-0.09 \mu \mathrm{g} \mathrm{mL}^{-1}$ and 0.09 $0.31 \mu \mathrm{g} \mathrm{mL} L^{-1}$, respectively. These data are shown in Table 2 .

3.3. Precision and Accuracy. The reproducibility, or intraassay precision, was assessed by repeatedly measuring the retention times and peak areas for six independently prepared samples of analyte. The reproducibility for all compounds was better than RSD $=1.00 \%$ for peak responses and better than RSD $=0.03 \%$ for the retention times (data not shown). Thus, the HPLC assay showed good repeatability under optimized conditions and this method was very stable. In addition, to test the precision and accuracy of our analytical method, the intra- and interday variations in the measurements of the six major constituents were determined; these are summarized in Table 3. Briefly, the 
TABLE 5: Content of the six marker compounds of Insampaedok$\operatorname{san}(n=3)$.

\begin{tabular}{|c|c|c|c|}
\hline \multirow{2}{*}{ Component } & \multicolumn{3}{|c|}{ Content $\left(\mathrm{mg} \mathrm{g}^{-1}\right)$} \\
\hline & Mean & SD & RSD (\%) \\
\hline 1 & 2.33 & $0.22 \times 10^{-1}$ & 0.96 \\
\hline 2 & 0.72 & $0.02 \times 10^{-1}$ & 0.29 \\
\hline 3 & 9.88 & $0.33 \times 10^{-1}$ & 0.34 \\
\hline 4 & 1.42 & $0.34 \times 10^{-1}$ & 2.42 \\
\hline 5 & 6.82 & $0.28 \times 10^{-1}$ & 0.41 \\
\hline 6 & 3.28 & $0.08 \times 10^{-1}$ & 0.24 \\
\hline
\end{tabular}

intra- and interday precisions were in the range $0.13 \%-$ $1.70 \%$ and $0.12 \%-2.56 \%$, respectively. The intraday accuracy was in the range $96.64 \%-106.51 \%$ and the interday accuracy was $96.04 \%-105.62 \%$. The recovery of the six components was in the range $92.62 \%-105.96 \%$ and the RSD was in the range $0.21 \%-3.89 \%$ (Table 4 ).

3.4. Sample Analysis. Our newly established analytical method was applied to the simultaneous determination of the six components of ISPDS. Figure 2 shows chromatograms of the reference components and a water extract of ISPDS, with detection of eluents at 254, 280, and $320 \mathrm{~nm}$. The amounts of compounds 1-6 (liquiritin, ferulic acid, naringin, hesperidin, neohesperidin, and glycyrrhizin, resp.) were $2.33,0.72,9.88,1.42,6.82$, and $3.28 \mathrm{mg} \mathrm{g}^{-1}$, respectively. The analytical results for each component identified are summarized in Table 5.

\section{Conclusion}

We have developed a simple and rapid HPLC method for the simultaneous separation and determination of six components of ISPDS to evaluate their quality in ISPDS samples. In this work, the simultaneous determination of these six marker compounds in ISPDS was validated with respect to linearity, precision, and accuracy. Our method will be of great usefulness improving quality control and analysis of ISPDS samples.

\section{Acknowledgment}

This research was supported by a Grant from the Korea Institute of Oriental Medicine (KIOM): The Evidence-based Medicine for Herbal Formula (no. K12031).

\section{References}

[1] H. Zhang, P. Shen, and Y. Cheng, "Identification and determination of the major constituents in traditional Chinese medicine Si-Wu-Tang by HPLC coupled with DAD and ESIMS," Journal of Pharmaceutical and Biomedical Analysis, vol. 34, no. 3, pp. 705-713, 2004.

[2] W. Y. Jiang, "Therapeutic wisdom in traditional Chinese medicine: a perspective from modern science," Trends in Pharmacological Sciences, vol. 26, no. 11, pp. 558-563, 2005.
[3] S. Liu, L. Z. Yi, and Y. Z. Liang, "Traditional Chinese medicine and separation science," Journal of Separation Science, vol. 31, no. 11, pp. 2113-2137, 2008.

[4] J. Hur, Donguibogam, Namsandang, Seoul, Korea, 8th edition, 2007.

[5] J. A. Lee, H. K. Ha, D. Y. Jung et al., "Comparative study of 25 herbal formulas on anti-inflammatory effect," The Journal of Oriental Obsterics \& Gynecology, vol. 23, no. 3, pp. 101-111, 2010.

[6] J. Y. Shim and B. W. Kim, "A study of effects of Insampaedoksan and Kammiinsampaedok san on the analgesia, antipyresis and thioacetamide induced liver damage in rats and mice," KyungHee University Oriental Medicinal Journal, vol. 7, no. 1, pp. 323-334, 1984.

[7] J. B. Weon, J. Y. Ma, H. J. Yang et al., "Quantitative analysis of compounds in fermented Insampaedok-san and their neuroprotective activity in HT22 cells," Natural Product Sciences, vol. 17, no. 1, pp. 58-63, 2011.

[8] H. A. Eum, J. H. Lee, D. S. Kim et al., "Acute toxicity study on Insampaedok-san extracts in mice," Korean Journal of Oriental Preventive Medical Society, vol. 14, no. 3, pp. 27-35, 2010.

[9] G. Y. Im, Y. H. Hwang, J. H. Lee et al., "Acute toxicity study on Insampaedok-san and fermented Insampaedok-san," Korean Journal of Oriental Preventive Medical Society, vol. 15, no. 3, pp. 141-152, 2011.

[10] J. Han, M. Ye, H. Guo, M. Yang, B. R. Wang, and D. A. Guo, "Analysis of multiple constituents in a Chinese herbal preparation Shuang-Huang-Lian oral liquid by HPLC-DADESI-MSn," Journal of Pharmaceutical and Biomedical Analysis, vol. 44, no. 2, pp. 430-438, 2007.

[11] A. Y. Park, S. Y. Park, J. Lee et al., "Simultaneous determination of five coumarins in Angelicae dahuricae Radix by HPLC/UV and LC-ESI-MS/MS," Biomedical Chromatography, vol. 23, no. 10, pp. 1034-1043, 2009. 


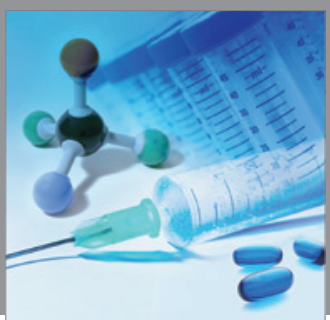

International Journal of

Medicinal Chemistry

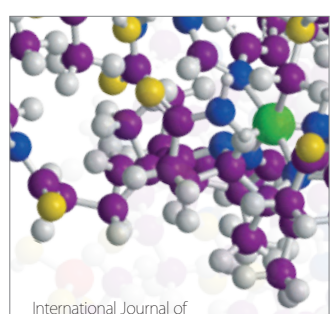

Carbohydrate Chemistry

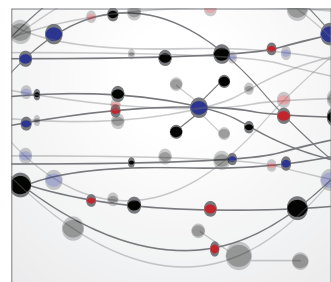

The Scientific World Journal
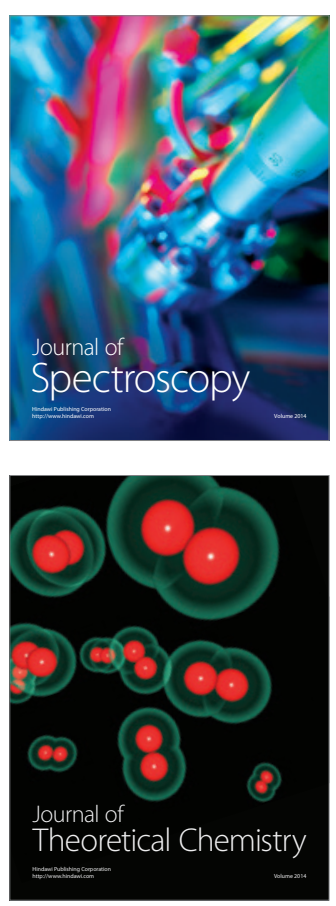
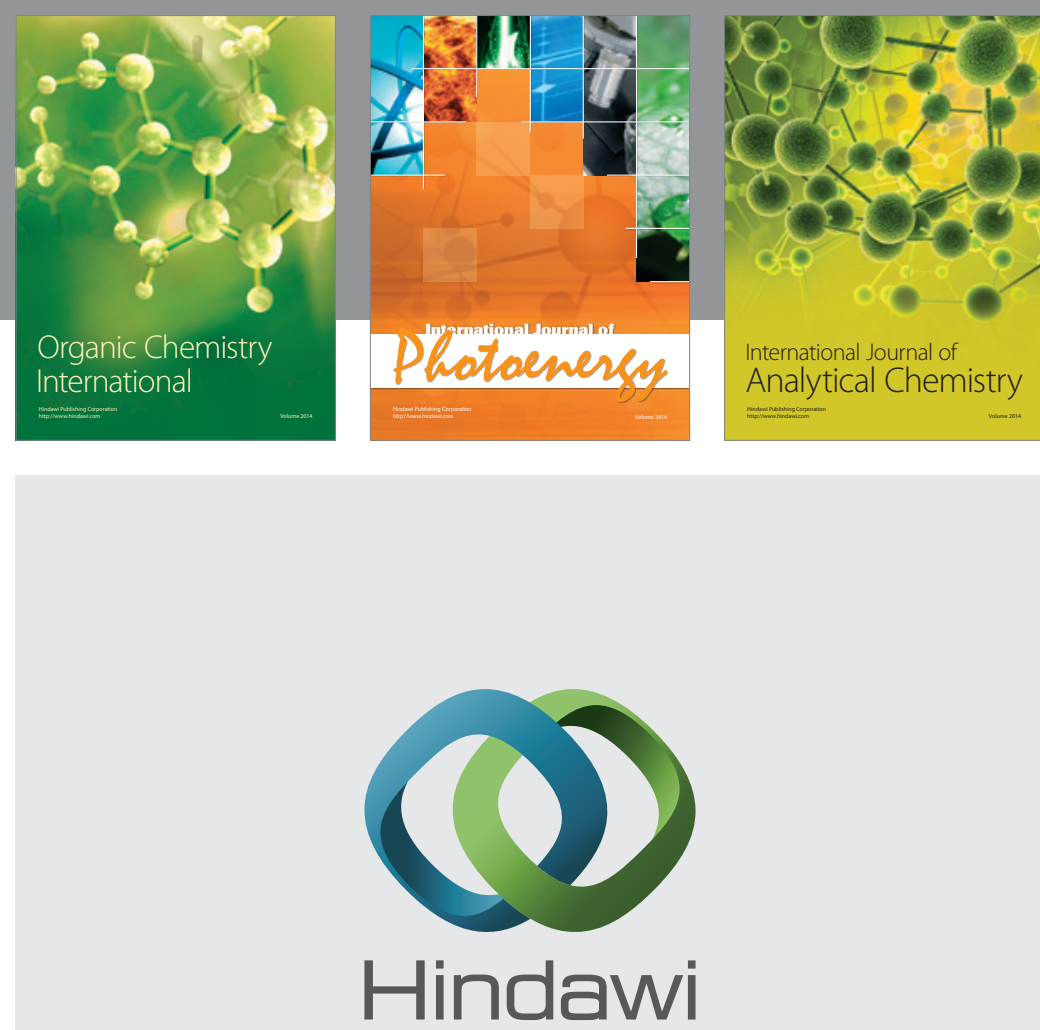

Submit your manuscripts at

http://www.hindawi.com
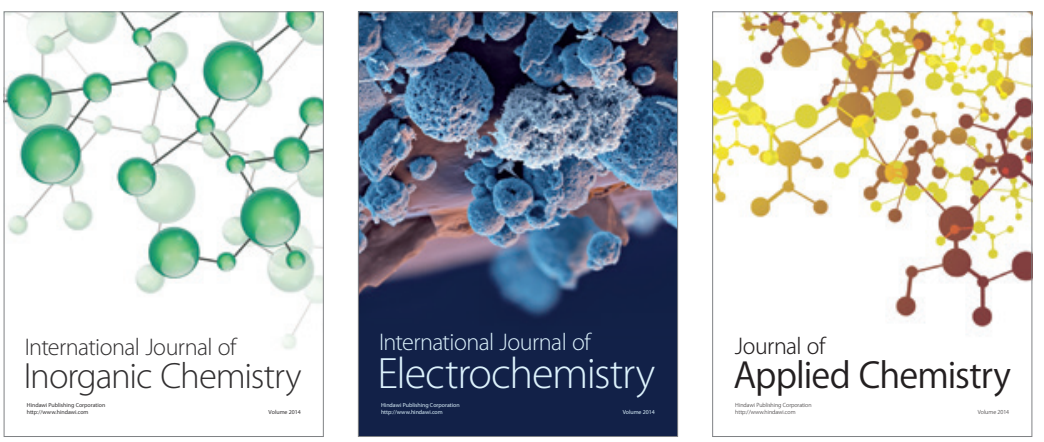

Journal of

Applied Chemistry
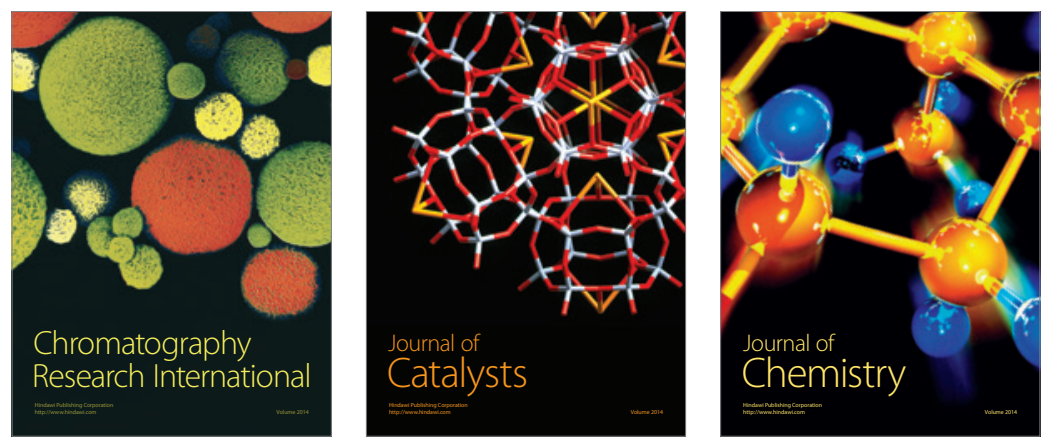
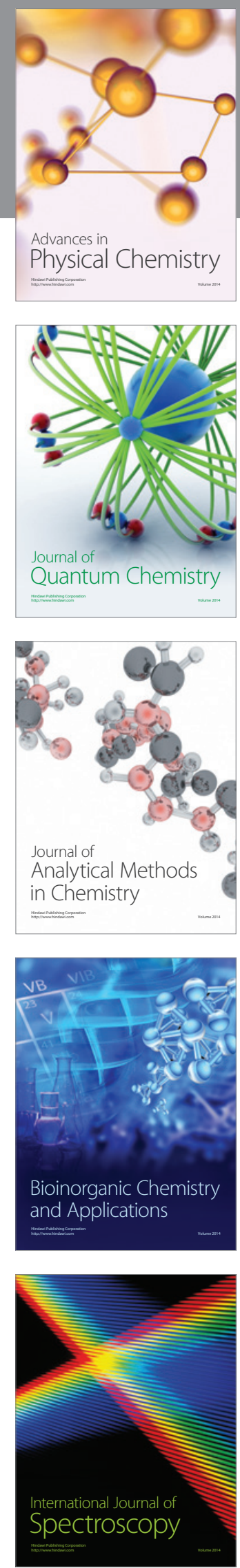